\title{
The Symphony of Communicative Approach \& World Englishes: A Study of the Involvement of Accents in English Listening Teaching
}

Sun Yanni

BA and an MA in English Language and Literature from Xi'an International Studies University, She is currently teaching English in Foreign Languages Department at Guangdong Polytechnic College. She has published several journal articles. Her interests include English Language and Literature, English varieties in listening \& interpretation.

Abstract: Immensely intensive cross-border trade in China has brought English to an unprecedentedly crucial status for communication. As a result, great variety of English accents mushroomed, which often baffles English learners. The thesis analyzes the English accents issue, World Englishes, in China under the guidance of communicative approach from three perspectives to show the definite necessity of involving accents in English listening teaching for the sake of achieving communicative efficiency and increasing multicultural awareness. Besides, some possibles methods have been brought up for the practical teaching process.

Keywords: communicative approach; English accents; world Englishes; multicultural awareness; English listening teaching

Published Date: January 2018

Published Online: $31^{\text {st }}$ January 2018

Corresponding Author: Sun Yanni, yanni.sun@foxmail.com

\section{Introduction}

With cross-culture communication in English being immensely intensive in China, great variety of English accents mushroomed. Yet the issue of various English accents often baffles English learners. Traditionally, English learning is modeled after British and North American Englishes. Yet, the globalization and localization challenged their status as "Standard". In this wave, Kachru's "World Englishes" theory has been brought up and exerted great influence. The thesis analyzes the English accents issue in China from three perspective: listening test, the practical English using situation in China, as well as the current situation of English listening teaching. An experiment has been conducted to testify that students who have been introduced with English varieties and sills apparently outperform those who have not. Based on the experiment, with communication being the ultimate goal of English learning in communicative approach, the thesis indicates the consciousness of involving accents in English listening teaching is in urgent need, and offers possibles methods on practical teaching.

\section{Literature review}

Globalization highlights the insurmountable status of English in cross-culture communication, which, as a result, stimulates the study of World Englishes, with the international journal World Englishes as the research outcome. The study in China started from 1990s, putting forward a term "Chinese English", followed with hot discussion. Three notable researches were conducted under the perspective of World Englishes. Whereas, few researcher offer report on the practice of World Englishes.

In Zhou Rong and Chen Guohua's collaborative report, by involving 101 Chinese English-major university students in two empirical studies, they investigated into the relationship among language vitality, language attitude and language behavior. 
Their research outcome turns to be an apparent preference of American English, yet a combination of accents in students' pronunciation. Another research is conducted by Gao Yihong and Xv Hongchen. With a subjective projection test about five English varieties, the research indicates that Chinese student volunteers have limited identification and knowledge of English varieties.

Jiang Yajun's "Englishes in the Past 20 Years" indicates native English speakers seem to have lost their exclusive privilege to control the standardization of the language. The paper researched on the various problems caused by the spread of English as international language. His collaboration work with Du Ruiqing, discussed some misunderstandings of issues concerned with the spread of English as an international language and offered a review of studies on English as an Asian language.

As a matter of fact, Globalization blurred the boundary among the inner, outer, and expanding circles of English. Since then, English varieties have received more wildly acceptance. As a result, according to Byram, the education to be a crosscultural citizen is becoming the aim of English education. ( Byram 2008:173) However, previous language attitude research indicates that Chinese university students turned to have an unanimous preference on British and North American accents. Other English accents, for instance, Australian, would be taken as nonstandard English.

Up till now, English varieties language databases have been established, for instance, the VOICE Vienna Oxford International Corpus of English; Corpus South-East Asian Englishes, with the help of International Association of World Englishes and The Macquarie Dictionary editorial committee. Another notable English accents database is Speech Accent Archive, founded by American scholar Steven $\mathrm{H}$. Weinberger in George Mason University. This corpus contains abundant English accents material with usually one passage read by speakers both from native English-speaking nations and non Englishspeaking area. These Corpus will provide a great convenience for a better understanding of English varieties, the World Englishes.
Besides, Listening and speaking are supposed to be the most crucial parts in communication. However, English listening teaching in China, for most of the time, is under estimated. In Teng Lifang's dissertation, English Listening teaching in China mainly adopts the following three steps: First, teacher read the direction; then students listen twice to complete the missing information or choose the right answer; and teacher will check the answer. From the interview, a large majority of students find it immensely boring and stressful. For English major students, some said it's a great relief to have only two hours a week. With three years English listening teaching experience of both English major students and non English major students, and also numerous empathic learning experience, I've noticed: most English listening teaching involves a passive listening process; few attention has been given to English accents; and most listening materials are transformed from a reading material. However, the three issues matter a lot in English listening teaching, which will be discussed later.

Recent years, international exchange in trade and culture, intercultural communication events are blossoming in China. Being the principle communicative language, English varieties haven't been given enough attention, which in fact matters a great deal in effective communication. Previous research have been mainly focusing on Chinese English, and students' attitudes on British, North American, and Indian Englishes. Few research have been done on the practice in English teaching. More empirical researches on the English teaching, and attitude \& intelligibility on World Englishes are waiting to be conducted.

\section{Theoretic framework}

Communicative approach is developed for foreign or second language teaching which highlights communicative competence as the goal of language teaching. Besides, communicative approach stresses learner's real life language.

Communication being the ultimate purpose of language learning, yet, English we speak possesses a fair number of varieties. American linguist Kachru 
divided English varieties into three Concentric Circles: inner circle, outer circle, and expanding circle.

The inner circle, including traditional English varieties (UK, US, etc.), is "norm-providing". English language norms are developed in these countries where English is the first language.

The outer circle (mainly New Commonwealth countries, including India, Malaysia, etc.) is "norm- developing". For the outer circle countries, English is not the native tongue, but is important for historical reasons, as an official language or otherwise.

The expanding circle (much of the rest of the world, including China, Russia, etc.,) is "norm-dependent". For the expanding circle countries, English plays no historical or governmental role, but is widely used as a foreign language.

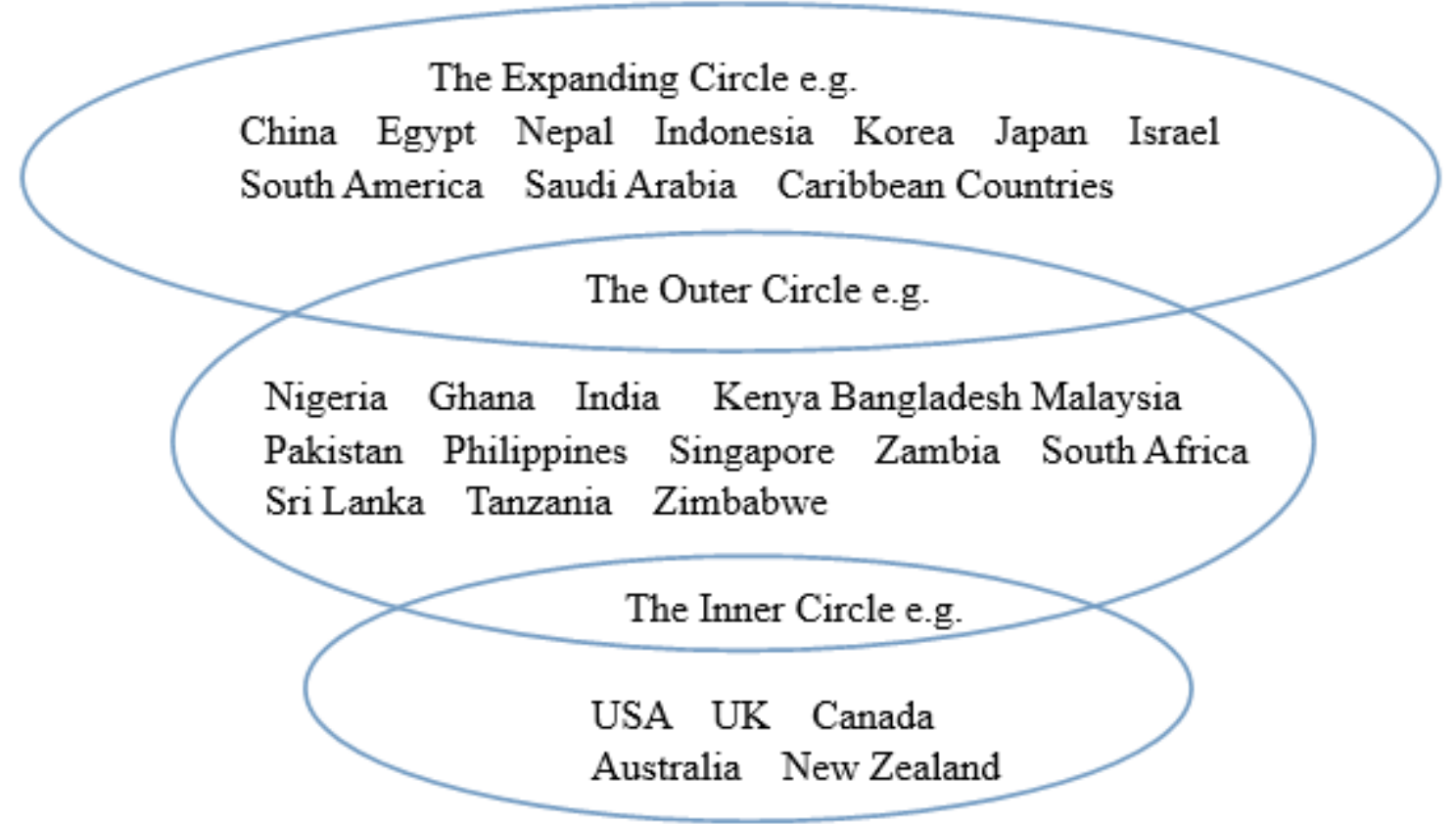

Figure I Kachru's Concentric Circles (Kachru 1997: 213)

Another observation is J. C. Wells' diagram which shows RP speakers occupy only a small proportion of the society. According to Trudgill's research in 1999, only about $9-12 \%$ of the population in U.K. speak standard English who belong to the tip of J. C. Wells' triangle. Therefore, probability of encountering standard British and American pronunciation is comparatively small, with a limited population of RP (Received Pronunciation) or GA (General American) speakers.

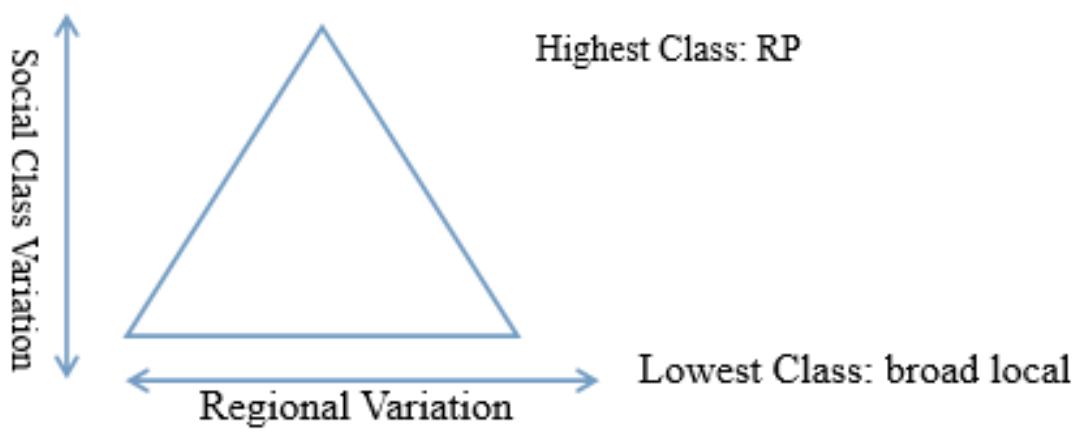

Figure 2 Two Parameters of an Accent

The above diagram indicates a huge population of non-native English speakers and consequently many possible English varieties in the world. Therefore, most people speak English with local or social accents. The huge range of English varieties put learners in an unfavourable situation where they are supposed to be familiar with and able to understand the World Englishes. 


\section{The involvement of accents in English teaching}

The thesis probes into the tricky English accents, or Englishes, and how these differences influence real English communication from three basic perspectives.

\subsection{Listening Test}

Initially, Globalization brought cultural diversity to a prominent position. As international language tests, to represent real life context, and conversational situation, a noticeable change has been made to current IELTS (International English Language Testing System) and TOEFL (test of English as a foreign language) listening tests by involving more English accents, for instance, Australian, Indian, Canadian, Japanese, even Middle East English accents, rather than the common British and North American accents, which requires higher English listening competence. The involvement of different English accents is for foreign student's ability to easily cope with people around the world, which indicates the scientificity and maturity of IELTS and TOEFL. The change is of great guiding significance to English listening teaching.

\subsection{The practical English using situation in China}

An even more notable issue about accents is the practical English using situation in China. The policy "One belt and One Road" brings prosperity for not only the economy but also the cultural exchange between China and middle \& south Asia, Middle East, as well as African countries. Under such circumstance, an enormous challenge emerges for those who are only familiar with British and American accents or overemphasize the necessity of acquiring the standard English: GA (General American) and RP (Received Pronunciation).

However, in real international communication, people who speak English have beyond the inter and outer circle. The standard English concept may cause obstacle for English learner's perception and interest of other English accents, the World Englishes. Having little familiarity with different English accents cause difficulty in understanding, even failure. For instance, some Indian, Turkish speaker's pronunciation of th $/ \theta / / \delta /$ might simply sounds like the dentalized $/ t /$. Most of the time, the voiceless plosive / $t$ / sounds like voiced plosive /d/. Indian English often lack plosive sound and pause, with a fast speed. An quite well-known joke in China about accent is, more often than not, the interpreters need to work collaboratively in a company to struggle with the negotiation with Indian company. The pressure from English accents was at its greatest, which exposes the problem in listening teaching. Besides, In Australian accent, words like paid, the (RP:/eI/) turns into /æı/ according to The Macquarie Dictionary Australian National Dictionary. Being familiar with and capable of handling different accents matters a great deal in business negotiation and government foreign affair reception.

Besides, an increasing number of intercultural communication events are held in China, for instance, Olympic Games, Group 20, Shanghai World Expo, etc., which require a great deal of English Volunteers, usually English major students. In Gao Yihong's research, She offers a detailed description of the volunteer's feeling of different English accents. According to her interview, Japanese pronunciation of "press kit" sounds pretty much like "press kito"; Indian English speaks very fast, with an unfamiliar intonation. One volunteer confessed that he failed in communicating with Arabic English. When an Egyptian athlete said a long sentence, he and another English major student from a Foreign Language Studies University asked the athlete to speak English. And this athlete replied "I am speaking English." Feeling rather embarrassed, they said sorry and left. These examples evidently indicate that inadequate and limited knowledge of English accents cause not only difficulty in understanding but also sometimes failure in communication.

Another typical situation is interpretation. According to Daniel Gile's Effort Model of interpretation, Interpretation basically involves three parts: Listening and Analysis, Short-term Memory and Coordination, and Production. Accented English brings difficulty in the interpreter's comprehension. As a person's attention span is limited, much effort given to the Listening and Analysis will cause 
inadequate attention to other missions, for example note-taking and memory, resulted in a reduced translation speed, accuracy, and quality.

Gile's Effort Model of consecutive interpreting perceives the interpreting process into two phases which can be presented in the following formula:

Phase I: $\mathrm{Cl}$ (listening) $=\mathrm{L}+\mathrm{M}+\mathrm{N}+\mathrm{C}$

Phase 2: $\mathrm{Cl}$ (reformation) $=\mathrm{Rem}+$ Read $+\mathrm{P}$

The explanation of the above elements in the formula is presented as follows:

- $\mathrm{Cl}$ : Consecutive Interpreting

- L: Listening and analysis

- M: short-term memory

- N: Note-taking the key information which could remind and help interpreter to retrieve information from memory.

- C: Coordination effort

- Rem: recall from memory and notes

- Read: reading notes taken in the first phase

- P: Production of the translation.

Zhao Qian in her dissertation studies the difficulties that accented English brings on interpreters' performance. She confessed that being an inexperienced interpreter, accented English is a great yet inevitable challenge, and often cause fear. Both of Zhao Qian and Wu Zhiwei's researches on accented English in interpretation indicate: first, accented English exerts considerably negative influence on effective interpretation; second, the mental state of anxiety, fear, and agitation on different levels, often results in being unable to concentrate on listening and analysis, even tumbling into a downward spiral of anxiety-failure in understanding-anxiety; ultimately, students who have a basic knowledge of accented English tend to have a significantly better performance than those who have not. With World Englishes, dealing with accented English will be a common yet thoughtprovoking issue. Therefore, being familiar with and capable of handling different accents matters a great deal, sometimes is even vital in effective communication.

\subsection{The current situation of English listening teaching}

In fact, English listening teaching in China attaches inadequate attention to English accents which weighs a lot in effective communication. The ultimate goal of language teaching is real communication, according to communicative approach, vice versa. Therefore, the consciousness of involving accents in English listening teaching is highly necessary in improving teaching quality, and attaining the goal of fostering the English language proficiency.

However, according to Liu Dongbiao's research on university English teachers' attitudes on standard English accents and other English varieties, university English teachers haven't been fully aware of English as an international language, World Englishes. More than $80 \%$ of teachers only take RP (Received Pronunciation) and GA (General American) as standard English accents, with other English varieties as unacceptable non-standard English.

Globalization and localization make English even more widely spread and used, forming different English Accents. Nowadays, within four English speakers, only one is native English speaker. Most of the time, English is used among Non-native speakers, or the outer and expanding circles. Therefore, for foreign language learners, the English learning is not simply imitation of native speaker's accent, but effective communication with both native and nonnative English speakers. In a survey "Whether your English teachers have taught you about accented Englishes", one out of six said "no, but he studied by himself", with most of the rest said no.

Ultimately, with the study of listening tests, as well as the practical English using situation in China, the necessity of involving English accents in English listening teaching is evidently demonstrated. Introduction and involvement of English Accents is supposed to be included into the syllabus. According to Kachru's three Concentric Circles, representative English accents may be selected to be introduced and trained in listening class to increase student's familiarity of different accents.

\subsection{Empirical evidence of involving accents in English listening teaching}


An experiment was conducted to certify the notable effectiveness of improving listening and communication proficiency on condition of involving English accents in English listening teaching. The hypothesis is that those students who have received the accent introduction and skills in the class significantly outperform those who have not, supposing other variables are the same or similar. Two groups of students, with each 4 girls and 6 boys, were involved in the experiment with the similar age, gender, same years of English learning, and similar listening proficiency after selection. Real conference recording was chosen as material for students. The speech in this experiment was taken from Malala's speech in General Assembly of the United Nations. Before the experiment, the experimental group was briefed about the Phonemic features of Pakistan English, and given a sample audio downloaded from the Speech Accent Archive website for reference. Besides an analysis of the features of Pakistan English, the experimental group was also offered an introduction of skills in dealing with unfamiliar accents, for instance, logical deduction from the topic, anticipation, tips from English logic and marker words.

Malala's speech was divided into three parts for the experimental test, followed with retellinginterpretation-retelling test. The students' performance in simultaneous interpretation laboratory was recorded for study. Their audio and video recordings are analyzed from three dimensions: accuracy, skills in dealing with accents, and emotion. The experiment outcomes turn to be: the experimental group has an overall better performance than the control group; above all, the accuracy of comprehension notably outperforms the control group in understanding each sense group; secondly, the experimental group have more confidence in handling the accented English, less degree of anxiety and agitation; thirdly, skills of anticipation, tolerance of vague information, and effect emotion adjustment contributed to the experimental group's outperformance.

\subsection{Methods for listening teaching.}

\subsubsection{Active process: anticipation}

Listening comprehension is a complex, and active process in which the listener must retain what was gathered in, and interpret it within the context of the utterance. Being an active listener requires students to activate contextual information and previous knowledge in listening, and think ahead of the speaker - anticipation.

Students need to develop the skill of keeping up with the speaker, even being ahead of the speaker. An active listener is constantly setting up hypothesis in his mind, and also, constantly testing his hypothesis by matching it with what he has heard in reality. Active thinking takes place all the way through. The skill of anticipation depends largely on the listener's familiarity with the theme and the setting.

Before actual listening, students could perhaps first give some thought to the topics, discuss it with others, read some related materials and do some vocabulary work. Helping students fully orientated for the forthcoming talks or lectures, may make them become effective listeners.

\subsubsection{Involvement of English accents, world Englishes in real materials}

For different accents, three measures could be taken. First, teachers could make an introduction and training of the representative English accents according to Kachru's three Concentric Circles. Next, dictation with different accents could be given to students as assignments, with a required error analysis to discriminate between same \& similar sounds, different accents of words, and phonetic features like linking sound and plosion. Also, real material with different English accents could be given to students to write an outline or do retelling. Real material in different types, for instance, interviews, reports, story, and conversation, could be used in listening teaching. Interview usually takes question and answer format. Conversation basically adopts topics and attitudes. Reports usually involve the basic elements and details. The methods mentioned above may be taken to make students capable of handling World Englishes in different topics and situation. 


\section{Conclusion}

By analyzing the English accents issue in China under the guidance of communicative approach and World Englishes from three perspectives, this paper indicates the necessity of involving accents in English listening teaching, as communication is the ultimate goal of English learning. The empirical evidence illustrates that unfamiliar accents exert negative impact on comprehension and interpretation, which influences the accuracy, emotion, and also the effort coordination according to Gile's effort model. The experiment certifies that one extra lesson of accented English do help improve students' listening proficiency of English varieties. Therefore, receptive World Englishes skills and multicultural awareness should be included in long-term language education as well as daily teaching practice. A better idea of English varieties will provide a more open attitude on languages and a great multicultural awareness. Hence, an effective communication can be achieved.

\section{References}

[1] Byram, M. From Foreign Language Education to Education for International Citizenship. Clevedon: Multilingual Matters. 2008:173.

[2] Gao, Yihong, and Xv Hongchen. "The Attitude of Chinese Student Volunteers towards World Englishes Before and After Intercultural Communication Events." Foreign Language Education Jan 35.1(2014). [3] Gao, Yihong, and Lin Mengxi. "Olympic Games Volunteers' Attitudes Towards World Englishes and Multicultural Awareness: An Investigation Before and During Beijing Olympic Games." Foreign Language of China Mar 7.2(2010):3-10.

[4] Gile, Daniel. Basic Concepts and Models for Interpreter and Translator Training. Amsterdam/Philadelphia: John Benjamins, 1995.

[5] Jiang, Yajun. "Englishes in the Past 20 Years." Foreign Language Teaching and Research Mar 1995: 13-19+80.

[6] Jiang, Yajun, and Du Ruiqing. "Issues about Chinese English: An Reply to Disagreement on the Nativization of English in China." Foreign Language Education Jan 24.1(2003):27-35.

[7] Kachru, B. B.. "World Englishes 2000: Resources for Research and Teaching." Smith and Forman, (eds), World Englishes: Seleced Essays. Vol.14, University of Hawaii. 2000:209-251.

[8] Liu, Dongbiao, and Liu Yi. "Research on University English Teachers' Attitudes on Different English Accents." Forward Position 306.4(2012).

[9] Teng, Lifang. "Communicative Approach Application of Listening Teaching in the New Curriculum Concept." Diss. Chongqing Normal University, 2011.

[10] The Macquarie Dictionary - Australia's national dictionary. (7th edition.) Macquarie, NSW: MacQuarie Library Pty. Ltd, Mar. 2017.

[11] Trudgill, P. (1999). "Standard English: what it isn't?" Tony Bex and Richard Watts, (eds) Standard English: The Widening Debate. London: Rutledge, 117-28.

[12] Wu, Zhiwei. "An Empirical Study on the Influence of Unfamiliar Phonemic Deviation on the English-to-Chinese Consecutive Interpreting Performance." Diss. Guangdong University of Foreign Studies, 2008.

[13] Wells, J. C.. Accents of English. Cambridge University Press. 1982

[14] Zhao, Qian. "The Impact of Accent on Interpreter Performance in Simultaneous Interpretation and Strategies in Light of Gile's Effort Model." Diss. BeiJing Foreign Studies University, 2014.

[15] Zhou, Rong, and Chen Guohua. "A study of Chinese university students \& attitude to American and British English." Modern Foreign Languages (Quarterly) February 31.1(2008).

\section{Appendix}

Questionnaire on attitudes upon English listening class and accented Englishes

1. What do you think of your English listening classes? (enjoyable and useful / not really useful / boring / stressful)

2. How many English listening classes do you have in a week?

3. Have you made listening practice a daily routine activity?

4. What's the listening teaching method that your 
teacher usually adopt?

5. Whether your English teacher has taught you accented Englishes? If so, what are they?

6. Have you ever learned about English varieties, for example, Australia English, Indian English?

7. Have you ever talked with or listened to accented English? How do you feel?

8. In your opinion, is it necessary to involve accented English listening material in listening class training?

9. Of the following strategies, which do you think might be effective in dealing with English accents? (language skills / extra language knowledge / other) 10. Will you take certain skill(s) when encountering a speaker with heavy English Accent? (yes, a bit / yes, not much / no, without relative training / not at all) 11. Will you take the following skills when listening to accented English? (logical deduction / omit / prediction / if you have others, please briefly explain) 12. Have you ever had such kind of training or practice to use such skills?(yes, often / yes, occasionally / no, seldom)

13. Do you think those student interpreters who have received the accent introduction in the class significantly outperform those who have not, supposing other variables are the same or similar? (yes / maybe / not really)

We appreciate your contribution. Thank you. 